\title{
Networking in Rural Environments: Benefits, Feasibilities, and Requirements
}

\author{
Yang $\mathrm{Li}^{1}, \mathrm{H}$. Anthony Chan ${ }^{2}$, and Johnson I. Agbinya ${ }^{3}$ \\ ${ }^{1,2}$ Department of Electrical Engineering, University of Cape Town, South Africa \\ ${ }^{3}$ Faculty of Engineering, University of Technology, Sydney, Australia \\ Emails: yli@crg.ee.uct.ac.za ${ }^{1}$,h.a.chan@ieee.org ${ }^{2}$, johnson.agbinya@uts.edu.au ${ }^{3}$
}

\begin{abstract}
Building networks in rural areas is difficult because of the tough rural environments and low return to the service operators on investment.

Rural networking and their applications in education, health, community development, and business development are essential to the daily life for both inhabitants and visitors. They further bring opportunities in job and business which play a key role in developing most underdeveloped rural areas. Moreover, rural communication will grow with the initial investment in rural networking. It will become the major communication market and generate large profits to service operators and equipment manufacturers.

Wireless networking is generally considered a solution to these difficulties in rural conditions. Compared with the wireline construction, setting up wireless networks is faster, more flexible, and less expensive. In addition, many new and advanced wireless technologies have enabled universal communication to rural and remote areas in a profitable manner. Yet special technological requirements need to be met for wireless networking to become feasible in rural areas.
\end{abstract}

Index Terms - Rural areas, communication system planning, network planning, social benefits.

\section{INTRODUCTION}

Information and Communication Technology (ICT) based services are no longer luxuries but are the drivers of essential life activities for both urban and rural dwellers. These technologies must be enabled by communication network. However, these networks have not been well developed in rural areas, and a shortage of rural networks has been hindering many countries from growing the local economies in rural regions. The scarcity of these basic telecommunication facilities come from many natural and artificial difficulties. The natural hardships include the difficult terrains and severe climatic conditions, which impose special and critical requirements to install and to maintain equipment outdoors. The artificial difficulties include the low-paying ability as

Manuscript received August 12, 2005.

This work is supported in part by Telkom, Siemens, and National Research Foundation, South Africa under the Broadband Center of Excellence program at University of Cape Town. many families in developing countries are enduring meager incomes. Nonetheless there still exist a number of ways for wireless network planners to immediately start economically efficient and technically optimal communications infrastructure in rural and remote areas.

The benefits, feasibilities, and requirements of networking in rural areas are described in this paper. An example of modeling rural networks using Global System for Mobile communication (GSM) is given in [1].

Rural areas present difficult communication environments (Section II). Despite these difficulties, there are many benefits of building wireless networks (Section III). After reviewing the currently available technologies (Section IV) we describe the requirements on building these rural networks (Sections $\mathrm{V})$.

\section{RURAL COMMUNICATION ENVIRONMENT}

Rural areas are covering the major part of mainland in most countries. Moreover, as is reported in [2], more than half of the world's population lived in rural areas by the year 2000. With the rapid development of the global economy, most rural areas are set to find their own ways of developing and they become more and more attractive to urban tourists and businessmen. Communications inside rural areas as well as with outside world, therefore, bear the brunt of many attentions and careful considerations. However, the procedures of networking in rural areas are always prohibited by their typical characteristics in network planners' views [3].

1) Difficult topographies, such as lakes, mountains, deserts, forests, and long distances between settlement areas, add to the cost and difficulties of constructing wireline telecommunication networks, and it is also hard to maintain networks in such areas.

2) Severe and changing climatic conditions impose heavy demands on the outdoor equipment such as the antenna and remote switch, adding to the costs of installation as well as maintenance.

3) Lack or absence of public facilities such as usable water, reliable electricity supply, access roads, regular transport, and an existing communication infrastructure will significantly increase the cost of the initial construction. 
4) The existing economic structure in rural areas is mainly based on agriculture and handicrafts, and few job opportunities exist. The resulting low-income and low ability of buying or paying restrict local people from the usage of communications.

5) Suffering from low educational levels and high illiteracy rates, the rural areas lack native technical personnel with even nominal telecommunication knowledge. On the other hand, hiring technical personnel from outside will definitely add to the cost of managing networks.

6) Despite the above inconvenience, there is a very high demand for voice communications as evidenced by long waiting lists and a steadily growing demand for data communications. Especially with the advent of the next generation networks (NGN), any user is supposed to use any service anywhere, so that rural areas will surely not be excluded.

The above-mentioned characteristics make it difficult for any network operator to put up the basic network infrastructure in rural areas. It is also difficult for service providers to provide public telecommunication services to rural network users with an acceptable quality by traditional means while achieving commercial viability.

However, the basic objectives to which telecommunication industries have to contribute are to trigger and sustain structural and economic development to minimize these disadvantages and generally improve the quality of life in rural areas. Besides, all aspects of benefits can be expected from exploring networking in rural areas.

\section{BENEFITS OF BUILDING RURAL NETWORKS}

Rural networks enable ICT so that the rural areas will be ICT-enabled with e-business, e-agriculture, e-government, emedicine, e-learning, and so on.

Despite many difficulties of constructing rural networks exist, building networks in rural areas can benefit all network involvers, including network users, planners, and constructers.

\section{A. Benefits to Customers}

Despite the miserable network environments in rural areas, rural inhabitants are expecting to communicate with the outside world to improve the quality of life and to generate business activity with people in other regions.

Good effects can be reflected in all aspects of their life. Some examples of these specialized rural applications are listed in the following [3].

1) Education part, which includes a) the delivery of multimedia contents to remote areas, b) virtual classroom using videoconferencing facilities, c) online academic databases, bibliographic access, and d) submitting tests online or by email.

2) Health and Medicine part, which includes a) the delivery of health information to medical professionals in the field, b) the delivery of prevention-oriented health information to rural communities, c) the entry of patient data into remote databases, and d) access to medical specialists via Tele-consultation.

3) Community Development part, which includes a) the creation and dissemination of local content, such as a multilingual web site, b) the dissemination of information about government programs, subsidies and administrative matters, and c) groups listening to radio broadcasts: special interests, sports, and entertainment.

4) Small Business Development part, which includes a) point-of-sale applications in remote tourist outposts (i.e. handcrafts).

5) Environment Monitoring and Protection part, which includes a) environmental information storage and exchange on the World Wide Web (WWW).

In fact, the contribution of networks to universal communication access in poor rural residential areas cannot be limited to these services. There are many other communication applications of wireless technologies in rural and remote areas, which can be added to the above list of applications.

Moreover, the installation of communication facilities in rural areas will not only bring benefits to inhabitants, but also to visitors from exterior regions. Examples are:

1) Tourists may feel more safe and comfortable if they are able to keep in touch with travel agencies at any time for any information such as to health, weather, geography, and so on.

2) Mining explorers or archaeologists equipped with timely and appropriate communications with central offices will be ensured of the proper procedure in their work.

3) In an emergency or disaster, it is necessary to get timely and valuable supports, such as calling police, fire brigades, and ambulance. In addition reestablishing communications in a short time after a disaster is also important.

All in a word, communication networks built within rural areas are beneficial to people who either stay in or travel to these areas in different ways.

\section{B. Benefits to Society}

From the view of the whole society, exploring the rural telecommunication market will not only resolve some of the current social problems but will also provide a solution to future social problems.

1) Solution to existing problems

Because of many difficulties mentioned in section II, rural areas have given much less emphasis than urban and suburban areas in planning national networks. Therefore rural telecommunication has been the bottleneck of the economic growth of underdeveloped areas, which is pictured in Fig. 1.

As is conceptually shown in the upper part of Fig. 1, many social function entities are needed to grow the economy of rural areas. These functions include education, health, and industry which require plenty of efforts and investments to develop. With the emergence of an information world today, 
these social functions are more and more dependent on communication networks. If basic communication or information exchange of these social entities is poorly developed, it becomes the bottleneck to economic growth. The development of these social functions will be correspondingly slowed down (lower part of Fig. 1). Then the entire economy of the rural areas will not prosper even with large investments in these social entities.

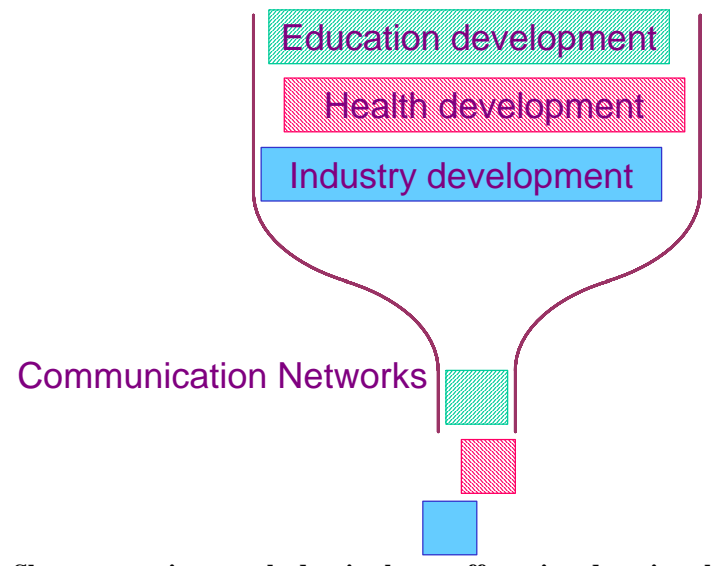

Fig. 1. Slow economic growth despite large efforts in education, health, and industry owing to the bottleneck caused by underdeveloped communication networks.

Rural areas often cover the larger part of the land, and in some countries such as China the majority of population are distributed in rural areas. Yet because most rural areas are underdeveloped, they are much less emphasized compared to cities ever since the country-wide networks are in the embryo stage. Such an imbalance in telecommunication development between rural and urban areas as illustrated in Fig. 2 should not be expected to contribute to the wellbeing of the entire country. An active and positive planning of rural networks is worth of execution.

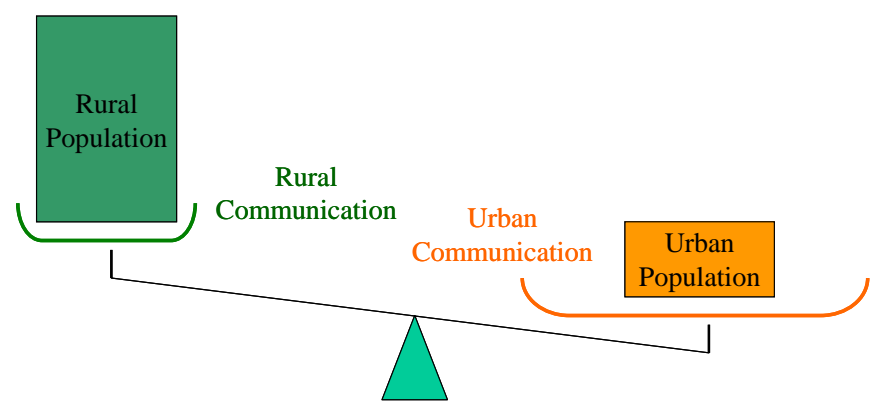

Fig. 2. Comparison between current rural and urban communications. Currently, rural telecommunications are much less developed than urban telecommunications even though there may be more population in rural areas than in urban areas.

\section{2) Solution to expected problems}

In the fast developing cities in some third-world countries, a massive migration of population from rural to urban areas is raising numerous social problems, including shortages of housing, worsening traffic jams, increasing crime rates, lack of space for relaxation and entertainment, and damage to natural environments.

Rural natives are migrating to urban areas because there are less jobs and business opportunities in the underdeveloped rural areas. Yet many rural businesses and job opportunities could have been enabled or enhanced by information technology (IT) today. When high speed communication networks are well-developed in rural areas, rural people will be able to access these IT-enabled or IT-enhanced jobs and businesses without the need to migrate. In addition, they will also be able to enjoy the benefits explained in Section III A of living in rural areas.

Conversely people in the overpopulated urban areas may choose to move back to rural areas. To seek a better quality of life, urban dwellers have increasing tendencies to find pristine rural areas to live while still enjoying all the benefits of modern life. For sure an ample amount of communication at their fingertip with relevant people is one of the most important modern-life manners these people care about. Only if a convenient contact with their boss, families and friends in town is ensured, would many urban dwellers prefer to live in rural areas to refresh themselves every day. This tendency is worth of the notice of network operators.

Moreover, the urban-to-rural-migration groups are different from other customer groups as shown in TABLE I in term of using communication facilities.

TABLE I

Communications-USAge PossibILITY AMONG THREe GROUPS

\begin{tabular}{lccc}
\hline \hline Customer Groups & $\begin{array}{l}\text { Long-term Service } \\
\text { (Strong Benefits) }\end{array}$ & $\begin{array}{l}\text { Short-term } \\
\text { Service } \\
\text { (Weak Benefits) }\end{array}$ & $\begin{array}{l}\text { High } \\
\text { Pay } \\
\text { Ability }\end{array}$ \\
\hline $\begin{array}{l}\text { Urban-to-Rural-Migration } \\
\text { Rural Natives }\end{array}$ & $\mathrm{X}$ & $\mathrm{X}$ \\
Rural-Visiting & $\mathrm{X}$ & $\mathrm{X}$ & $\mathrm{X}$ \\
\hline \hline
\end{tabular}

Unlike some local rural people, these migrating urban consumers have the affordability to purchase luxury communication services though living in rural areas. They also tend to use those services for long term usage in their life instead of for short-term usage by visitors. These urban-torural migrating groups should therefore be attractive to the network operators because the benefits from these migrating people to network investors can be calculated in the long run.

\section{Benefits to Operators}

From the government's perspective, the telecommunications industry not only benefits rural natives by providing them with communication services but also infuses power to drive other industries in undeveloped rural areas. As is explained in Section IIIA, a wide array of existing or new telecommunication applications is being created to meet local rural requirements, and they are affiliated to rural development efforts. With the applications for customers, the growth of communications industry may assist in improving health 
system, enhancing an all-sided education mechanism, encouraging regional business, and monitoring and controlling natural environments in rural areas. That way, rural communications attract network operators or telecommunication carriers not only from themselves but also from the deep impact they have on other industries. Take for example the effects of the wireless communication industry on IT fields. The manufacturing of multimedia mobile terminals of wireless industry creates jobs for cell applet programmers, the sales of communication services package provide positions for IT marketing personnel, and so on.

\section{Benefits to Manufacturers}

From the perspective of some service providers and equipment manufacturers, it is unfortunately not yet productive to build costly wireless networks on non-beneficial rural areas. They have to spend a huge amount of money and labor on the design, construction, management and maintenance of a wireless network in rural areas, but only get little return from what have been done.

On the other hand, if the priority is to develop rural economies, installing communication systems will yield benefits because there will be a drastic growth in the number of customers who expect easier and better communications in both their life and work. The future service demands from rural natives will increase to as high as that of those service requirements from urban areas today. The service operator or manufacturers who have explored the rural areas in advance will then find it easier and more handy to make profits and to reinvest on the new points of growth in the field of communications.

Therefore the problem for network planners at the moment is to first set up basic wireless networks in rural areas at an affordable cost. The basic networks are able to offer universal voice services to most rural population and cost them little to enjoy these services. As time goes by, these rural areas are prone to expand and develop into comparatively wealthier areas. By then the wireless communication requirements from local people will go up high enough to interest planners and investors. In other words, profits from rural customers in the long run can be expected for all network planners.

Some service providers and application developers have indeed been interested in investing in rural areas. These wireless companies intend to "give rural wireless customers better service and more choices” [4].

\section{Available Communication Technologies}

Although rural networking is quite beneficial to all network involvers, it remains difficult to choose a proper rural networking manner with respect to the various inconveniences of rural areas (refer to section II). Wireless communications, however, appear to be able to overcome the difficulties of laying rural networks as well as to bring in cheap and feasible communication for rural inhabitants.
Several wireless access technologies can be deployed in rural areas. In the following we mention the various possible technologies in rural areas and their characteristics.

1) High Frequency Radio (HF Radio), including Very High Frequency radio (VHF) and Ultra High Frequency radio (UHF), have been serving rural areas with wireless services for a long time. However, it is limited to a great extent in data rate because it uses narrow band packets [6].

2) GSM on 400MHz (GSM400) uses the frequency spectrum at $400 \mathrm{MHz}$ rather than the usual $900 / 1800 \mathrm{MHz}$ frequency spectrum to ensure a wider coverage area. This characteristic of GSM400 works for rural areas with wide areas and low population density [3]. In addition, GSM400 can be upgraded to $3 G$ or even $4 G$ via the evolution of General Packet Radio System (GPRS). However, GSM is costly. GSM/GPRS Network in Box (GSM/GPRS NIB) integrate all key components of a GSM system in a light, portable box, which deserves the name of a material solution to apply GSM in rural areas.

3) Code Division Multiple Access on $450 \mathrm{MHz}$ (CDMA450) operates at the $450 \mathrm{MHz}$ frequency spectrum range using code-division multiple-access technology. It will cover wider areas compared with other CDMA systems, and it is also easy to be upgraded to the future generations of wireless networks [3].

4) Fixed Wireless Access (FWA) technology can be used for the "last mile" in network construction to rural and remote areas [7]. It will enable use of both wireline and wireless LAN within the rural areas. Examples of communication enabled this way include wireline phone, cellular phone, Personal Handyphone System (PHS), or Digital Enhanced Cordless Technology (DECT).

5) The earlier version of Wireless Microwave Access (WiMAX) technology is an example of FWA with the distance scale of MAN. It forms the backhaul to the cellular phone network. Later enhancements have included mobility so that WiMAX is not limited to a FWA technology. It may become the future and less expensive cellular network. The larger distance range and the lower cost will become attractive for rural areas.

6) WLAN offers low cost and ease of installation needed for rural areas. While one single LAN may only have a range of up to about 100 meters, a mesh network of WLANs can cover a larger area. With the 802.11n WLAN standard of over $100 \mathrm{Mbps}$, it will be possible to supply integrated multimedia services to rural areas.

7) Satellite network is a good option to reach users over wide rural areas because of its unique characteristic of ultra broad area coverage. Very Small Aperture Terminal (VSAT), compared with other satellite family members, is more convenient for rural people because of its lighter and more portable terminals and lower price [8]-[10].

8) Multiple Input Multiple Output (MIMO) increases the 
communication capacity and improves the spectral efficiency of the network by transmitting radio signal on communication link with multiple antennas at both transmit and receive ends without using extra transmission power [11]. Signal can then be transmitted in good quality to as far as rural and remote areas.

9) The Fourth Generation (4G) Wireless network aims to provide various communication services via different access networks to users who have heterogeneous devices. Because it integrates all existing networks such as WLAN, Internet, Universal Mobile Telecommunications System (UMTS), Data Audio Broadcast/Data Video Broadcast (DAB/DVB), and Satellite, the $4 \mathrm{G}$ network is able to serve as wide area as possible, showing great benefits to open rural areas [12]. With the technologies of Orthogonal Frequency-Division Multiplexing (OFDM), MIMO, and Soft Defined Radio (SDR), 4G network affords data and image streaming at a high downlink speed of over $100 \mathrm{Mbps}$ outdoors [13]. Directly deploying 4G to rural areas will help rural areas to jump over the voiceonly communication stage and provide rural people with voice, data, and multimedia services at one time.

\section{REQUIREMENTS OF BUILDING RURAL NETWORKS}

The rural conditions as explained in Section II put the following requirements on rural networking.

\section{A. Requirements owing to the natural rural conditions}

The large rural areas and their severe conditions pose the following requirements on the network:

1) Distance scale: The network needs to cover a large rural area with the distance scale of a wide area network (WAN) or at least the equivalent distance scale of metropolitan area network (MAN).

2) Signal transmission: The network needs to operate in diverse geographic terrains, including forest and mountains. The wireless communication need to overcome the signal attenuation under these conditions. Inner interference from the same frequency or neighboring channel is minimal due to low rural user density, but outer interference hampers network quality by the long time transmission of signals.

3) Robustness: The network needs to function under extreme climate conditions, including high humidity, fog, and thunderstorm. The radio frequency (RF) signals need to withstand the attenuation, diffraction and refraction from fog and rain, so that a lower frequency RF is preferred. The RF signal transmission needs to survive or to recover from the severe Electromagnetic Interferences (EMI) caused by thunder. The network equipment also needs to survive the Electrostatic Discharge (ESD) and Electrical Overstress (EOS) caused by thunders.

\section{B. Requirements owing to the rural communication conditions}

The technology needs to function in areas lacking basic facilities such as electricity, road, and wireline infrastructure. The subsequent requirements are therefore:

1) Ease of installation: With no or limited access roads and means of transportation, the technical people may need to carry the equipments to install at remote rural areas. The equipments are preferably light, small, all-in-a-box.

2) Power source: The equipment often needs to have low power consumption due to limited electricity supply. Other energy supplies such as solar cells and wind generators are preferred.

\section{Requirements owing to rural people's situation}

People in rural areas currently often lack technical skills and training. They often lack technical people and can hardly afford to hire skilled people from outside. Yet they need communication to enable their life activities, to create jobs and business opportunities, and to grow their economy. Consequently, the requirements are:

1) Need of Services: High-quality voice, data, multimedia, or a mix of them is expected in rural networks to ensure a basic communication between two or multiple parties. There is more need for voice and multimedia in rural areas with low literacy rate.

2) Ease of operation, maintenance, and upgrading: Lacking technical people locally and lacking expensive technical support from outside, the rural areas need the networks that are easy to use and require minimal efforts to manage. The infrastructure also needs to be upgraded easily.

3) Cost of construction, operation, and maintenance: Owing to a low economic paying ability in rural areas, a low cost on both initial construction and lifetime operation are needed for the networks and terminals.

4) Scalability: The customer base in rural areas is growing very fast. The technology, capacity, and the deployment need to support both the initially smaller market and the subsequent growth in future rural communication market.

\section{General requirements on a communication network}

In addition to the above requirements specific to rural conditions, there are requirements applicable to a communication network in general.

1) Quality of Service (QoS): QoS generally refers to all-sided quality requirements on communication networks, such as jitter, latency, and bit-error rate. These requirements will be based on the particular communication applications [14].

2) Network capacity: Sufficient network capacity and wide network coverage provide far-ranging access to communications for rural people who are distributed over large areas. 


\section{CONCLUSIONS}

Rural populations constitute large proportions of national populations and their communication requirements are increasing every day in all fields of their life [15]. Some government, network operators, and service suppliers have realized that a big potential wireless market does exist in rural areas and have begun to take active interest in the fundamental construction of rural communication networks. There are longterm benefits to the customers, the society, the operators, and the manufacturers.

Numerous wireless technologies have contributed to the feasibilities of rural networking. Yet rural environments present specific networking requirements owing to their natural conditions, the existing communication conditions, and the inhabitants' situations. In addition, the requirements of rural networking are different from and are in addition to those of general networking.

\section{REFERENCES}

[1] Y. Li, J. I. Agbinya, and H. A. Chan, "An Applicable GSM Service Model for Rural Networking," African Journal of Information and Communication Technology, Vol. 2, No. 2, Jun. 2006, pp. 56-62.

[2] G. Lius and Romero-Font, "The use of Cellular Radiotelephone networks to provide basic exchange individual line telephone service in rural and suburban areas and as an emergency back-up system to the public switched network in cases of natural disasters," PTC 1988, pp. 357-362.

[3] ITU-D Group7, "New technologies for rural applications final report of ITU-D Focus Group 7,” 2000. Available: www.itu.int/ITUD/fg7/pdf/FG_7-e.pdf.

[4] B. Cubin, "Cubin introduces rural wireless regulatory relief bill: Rural wireless telecommunications enhancement act limits FCC rules on rural carriers,” $2002 . \quad$ Available: http://www.house.gov/cubin/news/2002/March21.html.

[5] Y. Li, "Models and Applications of Wireless Networks in Rural Environments," M.S. thesis, Dept. Computer Science, Univ. of the Western Cape, R. SA, 2004.

[6] Mpirical Ltd. "Mpirical companion version 6.1," 2004. Available: http://www.mpirical.com/companion/mpirical_companion.html.

[7] O. Momtahan and H. Hashemi, "Performance and capacity evaluations of DECT, PACS, and PHS standards for Wireless Local Loop applications," IEEE 50th Vehicular Technology Conference (VTC), vol. 1, Sep. 1999, pp. 523-527.

[8] J. R. Emani, "Very small aperture terminal or VSAT," Dec. 2002. Available:

http://www.bsnl.in/Knowledgebase.asp?intNewsId=5047\&strNewsMore $=$ more.

[9] R. Browne, "Very small aperture terminal (VSAT) satellite technology," $2004 . \quad$ Available: http://www.govcomm.harris.com/solutions/marketindex/product.asp?sou rce=alpha\&product_id=269.

[10] S. Nishimura and S. Inoue, "A very small aperture terminal,” Mitsubishi Electric ADVANCE, vol. 86, Jun. 1999, pp. 25-26. Available: http://global.mitsubishielectric.com/pdf/advance/vol86/86th2.pdf.

[11] A. van Zelst, "Physical Interpretation of MIMO Transmissions", Proc. Symposium IEEE Benelux Chapter on Communications and Vehicular Technology, 2003.

[12] H. Aghvami, “A Vision for 4G," Available: http://www.ctr.kcl.ac.uk/short-courses/4G_presentation.ppt

[13] D. X. Han, Y. C. Zhang and J. Cao, "The applications of next generation mobile communication on wireless local area network,” Available: http://telecom.chinabyte.com/226/1806226.shtml.

[14] B. Mitchell, "Wireless/Networking: QoS," 2004. Available: http://compnetworking.about.com/library/glossary/bldef-qos.htm.
[15] M. Kibati, "Wireless local loop in developing countries: Is it too soon for data,” M.S. thesis, Massachusetts Institute of Technology, USA, 1999.

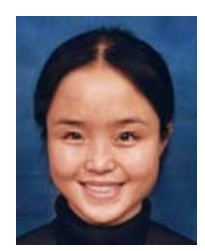

Yang Li received her B.Eng. from Beijing University of Posts and Telecommunications, P.R.China in 2001, and her M.Sc. from the University of the Western Cape, RSA in 2005, and is currently studying for a Ph.D. in the Dept. of Electrical Engineering, University of Cape Town, South Africa.

From 2001 to 2002, she was an assistant Engineer in the Technical Division of former SCNB, where her work focused on upgrading the intelligence part of the EWSD switch.

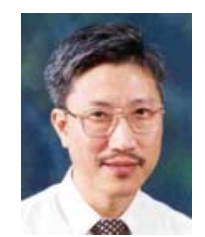

H. Anthony Chan received his $\mathrm{PhD}$ in physics at University of Maryland, College Park in 1982 and then continued post-doctorate research there in basic science.

After joining the former AT\&T Bell Labs in 1986, his work moved to industry-oriented research in areas of interconnection, electronic packaging, reliability, and assembly in manufacturing, and then moved again to network management, network architecture and standards for both wireless and wireline networks. He designed the Wireless section of the year 2000 state-ofthe-art Network Operation Center in AT\&T. He was the AT\&T delegate in several standards work groups under 3rd generation partnership program (3GPP). During 2001-2003, he was visiting Endowed Pinson Chair Professor in Networking at San Jose State University. In 2004, he joined University of Cape Town as professor in the Department of Electrical Engineering.

Prof. Chan was Administrative Vice President of the IEEE CPMT Society and has chaired or served numerous technical committees and conferences. He is a distinguished speaker of the IEEE CPMT Society and has been in the speaker list of the IEEE Reliability Society since 1997

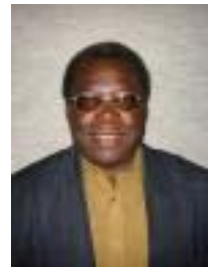

Johnson I. Agbinya is an Adjunct Professor of Computer Science at the University of the Western Cape, Cape Town South Africa and Senior Lecturer at University of Technology, Sydney, Australia Johnson I. Agbinya received his PhD in Electronic Engineering at La Trobe University in 1994 and subsequently joined Australia's Premier Research Institute, Commonwealth Scientific and Industrial Research Organisation (CSIRO) as a Senior Research Scientist where he undertook research in biometrics, pattern recognition and signal processing. At CSIRO he developed patented speech recognition and face recognition systems. He joined Vodafone Australia in 2000 as a Principal Engineer responsible for its industrial research administration on mobile and wireless communication where he served as its sole representative in several international standard bodies and the Australian Telecommunication CRC Executive Committee. He also contributed to Vodafone Australia's preliminary design of 3G radio access network in the Emerging Technologies Group. He has represented Vodafone Australia in the Vodafone Research Group from where he was spotted and appointed as Adjunct Professor in 2002 at the Department of Computer Science, University of the Western Cape (UWC). He is a key member of the Telkom / Cisco Centre of Excellence in Internet Computing at UWC and a rated researcher by the National Research Fund (NRF, South Africa).

Prof. Agbinya is currently a Faculty member in Information and Communication Group at the University of Technology, Sydney. His research interests are in wireless communications, application of biometrics in digital identity management systems and behaviour tracking in video, networks on mobile platforms (and in uncovered areas) and sensor networks. 